\title{
Review of Biosimilar Trials and Data on Etanercept in Rheumatoid Arthritis
}

\author{
Laura Chadwick $^{1} \cdot$ Sizheng Zhao ${ }^{1}$ Eduardo Mysler ${ }^{2} \cdot$ Robert J. Moots $^{1,3}$
}

Published online: 9 November 2018

(C) The Author(s) 2018

\begin{abstract}
Purpose of Review Etanercept was the first tumour necrosis factor inhibitor approved to treat rheumatoid arthritis (RA) in the United States (US) and Europe. The recent patent expiration of the etanercept originator ENBREL in Europe has facilitated the development of biosimilar products, creating the prospect of reduced treatment costs. In this article, we review the original trials for etanercept in RA to facilitate critical appraisal of biosimilar trial data.

Recent Findings Two etanercept biosimilars are currently approved in Europe and/or the US, SB4 (Benepali) and GP2015 (Erelzi), having met the pre-specified equivalence criteria for biosimilarity. Trial data demonstrates subtle differences in clinical outcomes and adverse events between the biosimilars and the reference product (RP).

Summary The development of etanercept biosimilars may reduce the financial burden of treating RA, but real-world data regarding efficacy and safety in comparison to the RP will be vital to assess for meaningful differences.
\end{abstract}

Keywords Etanercept $\cdot$ Biosimilar $\cdot$ Rheumatoid arthritis $\cdot$ ENBREL $\cdot$ Benepali $\cdot$ Erelzi

\section{Introduction}

Rheumatoid arthritis (RA) is a chronic autoimmune disease characterised by systemic inflammation which can lead to progressive joint damage and deformity if left untreated. Significant advances in RA treatment came with the introduction of biologic disease-modifying drugs (bDMARDs) such as tumour necrosis factor inhibitors (TNFi). The etanercept biooriginator, ENBREL, was the first TNFi to gain approval from the United States (US) Food \& Drug Administration (FDA) and the European Medicines Agency (EMA) for the treatment of moderate to severe RA in 1998 and remains a first-line bDMARD therapy for RA worldwide. Additional licenced

This article is part of the Topical Collection on Biosimilars

Robert J. Moots

rjmoots@liv.ac.uk

1 Institute of Ageing and Chronic Disease, University of Liverpool, Aintree University Hospital, Longmoor Lane, Liverpool L9 7AL, UK

2 Organización Medica de Investigación, Buenos Aires, Argentina

3 Department of Musculoskeletal Biology I, Institute of Ageing and Chronic Disease, Aintree University Hospital, Clinical Sciences Centre, Longmoor Lane, Liverpool L9 7AL, UK indications for etanercept include plaque psoriasis, psoriatic arthritis, ankylosing spondylitis, axial spondyloarthritis and polyarticular juvenile idiopathic arthritis [1].

Whilst the introduction of TNFi revolutionised RA treatment, the associated financial burden is significant; the cost per patient per year for ENBREL is $£ 9295$ in the United Kingdom (UK) [2] and estimated at $\$ 15,345$ in the US [3]. There has been great interest in the development of molecules with biological similarity to bio-originator bDMARDs, known as biosimilars, as patent expiration for bio-originator TNFi's began with ENBREL in 2015 in Europe (the patent in the US has been extended until 2028) [4]. The introduction of biosimilars into clinical practice will significantly improve the financial cost of RA treatment worldwide.

Biosimilar products must prove high similarity in safety, purity and potency to obtain regulatory approval $[5,6]$. This can be achieved through phase I and phase III clinical trials in which the bio-originator and biosimilar are directly compared to confirm equivocal efficacy and safety against pre-specified margins [7]. However, subtle differences in efficacy and safety outcomes have been noted in key comparator trials, and the potential clinical implications for this in daily practice are yet to be established. Moreover, when a biosimilar product has obtained licencing for one indication for which the biooriginator is already approved, the licencing can then be 
extrapolated to all other licenced indications for the biooriginator without further head-to-head comparative clinical trials. On-going vigilance by clinicians in reporting adverse events (AEs) and treatment outcomes is therefore vital.

This article summarises the pharmacology and clinical efficacy of etanercept (ENBREL) to facilitate a critical review of the data regarding the safety and efficacy of etanercept biosimilars for RA, focusing on products approved by the EMA and FDA.

\section{Pharmacology of Etanercept}

Etanercept is a fully human dimeric fusion protein consisting of the human Fc portion of IgG1 linked to the extracellular ligand-binding domain of the TNF p75 receptor, produced using recombinant DNA technology in a Chinese hamster ovary line cell line [8]. The structure of etanercept is depicted in Fig. 1.

Etanercept is administered via subcutaneous injection reaching peak serum concentration at $48-60 \mathrm{~h}$ with an elimination half-life of $70-100 \mathrm{~h}$. The volume of distribution is small although it is able to penetrate the synovium $[9,10]$. The mechanism of action is via binding to TNF, competitively inhibiting TNF from binding to cell receptors and preventing pathway activation [11]. The dimeric structure allows the molecule to bind to two TNF molecules at an affinity more than 50 times that of naturally occurring monomeric forms [8]. The immunogenicity of etanercept is reported to be very low, supported by a recent multi-national cross-sectional study in which no patients on etanercept $(n=200)$ developed anti-

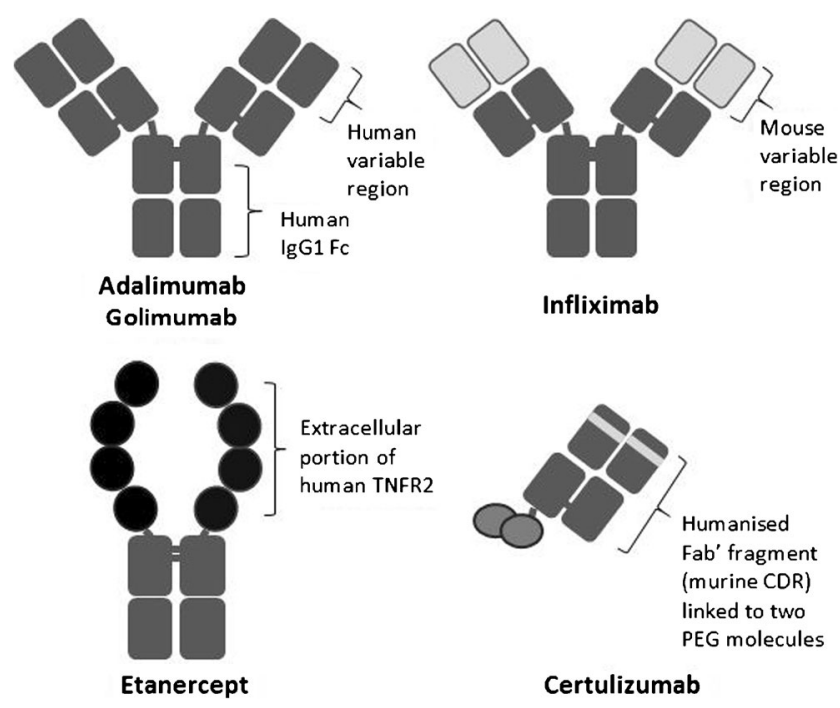

Fig. 1 Etanercept structure compared with other TNFis. TNFR2 TNF receptor 2, Fc fragment crystallisable region, $\mathrm{Fab}^{\prime}$ antigen binding fragment, CDR complementarity-determining region, $\mathrm{PEG}$ polyethylene glycol drug antibodies (ADAs) compared to $31 \%$ and $17 \%$ of patients on adalimumab and infliximab, respectively [12].

From this point onwards, "etanercept" in clinical trials refers to the reference product (RP) ENBREL unless otherwise stated.

\section{Clinical Efficacy of Etanercept}

The clinical efficacy of etanercept for RA has been assessed in several randomised controlled trials (RCTs) and open label extensions [13-19] (Table 1). Clinical response was measured using a variety of outcome measures, commonly including American College of Rheumatology (ACR) response criteria (ACR20, 50 and 70 requires a 20\%, 50\% and $70 \%$ improvement in the defined response parameters respectively [20]), 28 joint count disease assessment score (DAS28) remission (< 2.6) and patient-reported physical disability assessed via Health Assessment Questionnaires (HAQ). Radiographic progression was measured by modified or original total Sharp score. Unless otherwise specified, the clinical trials below used a dose of etanercept $25 \mathrm{mg}$ twice weekly, as noninferiority to the current recommended dose of etanercept $50 \mathrm{mg}$ weekly was not demonstrated until 2004 [16].

Etanercept, as monotherapy or in combination with MTX, has consistently been shown to be superior to placebo [13, 14, 16]. Etanercept monotherapy has shown relatively similar efficacy to MTX monotherapy in both patients with early RA ( $<3$ years duration; the TEMPO study) [15] and in patients with long-standing RA [17] with similar ACR20 responses at 52 weeks. However, in the TEMPO study etanercept monotherapy showed greater ACR responses at 24 weeks compared to MTX, suggesting a more rapid onset of improvement. In the TEMPO extension radiographic progression was lower in the etanercept group at 100 weeks with no significant infections or malignancies [21].

Etanercept-MTX combination therapy has consistently been shown to be superior to either etanercept or MTX monotherapy regarding clinical outcomes and radiographic progression with no significant difference in rates of serious infection or malignancy $[14,17,18,21,22]$. This includes the COMET study, with a patient population of early $(<2$ years) moderate to severe RA who were MTX naïve and was the first RCT using the $50 \mathrm{mg}$ weekly dose [18], the TEMPO study outlined above [17, 21] and patients with long-standing RA [14]. Similar findings with respect to monotherapy were also reported with regard to sulfasalazine (SSZ), although patients receiving etanercept experienced significantly higher rates of infections and non-infectious AEs compared to SSZ alone [19].

There are no head-to-head RCTs between etanercept and other bDMARDs. Multiple systematic reviews and metaanalyses comparing efficacy and safety of etanercept and 
Table 1 Randomised controlled trials of etanercept in rheumatoid arthritis

\begin{tabular}{|c|c|c|c|c|c|}
\hline Study & $\begin{array}{l}\text { No. of } \\
\text { participants }\end{array}$ & $\begin{array}{l}\text { Disease } \\
\text { duration }\end{array}$ & Treatment groups & $\begin{array}{l}\text { Study } \\
\text { duration }\end{array}$ & Outcomes assessed \\
\hline $\begin{array}{l}\text { Moreland } 1999 \\
\text { [13] }\end{array}$ & 246 & $\begin{array}{l}\text { Mean } \\
12 \text { years }\end{array}$ & $\begin{array}{l}\text { ETN } 10 \mathrm{mg} \text { twice/week } \\
\text { ETN } 25 \mathrm{mg} \text { twice/week } \\
\text { Placebo twice/week }\end{array}$ & 6 months & $\begin{array}{l}\text { Primary endpoint: ACR20, ACR } 50 \\
\text { ACR 70, tender/swollen joint counts, pain VAS, } \\
\text { physician/patient global, duration morning } \\
\text { stiffness, HAQ } \\
\text { Adverse events }\end{array}$ \\
\hline $\begin{array}{l}\text { Weinblatt } 1999 \\
\quad \text { [14] }\end{array}$ & 89 & $\begin{array}{l}\text { Mean } \\
13 \text { years }\end{array}$ & $\begin{array}{l}\text { ETN } 25 \text { mg twice/week + MTX } \\
\text { Placebo twice/week + MTX }\end{array}$ & 6 months & $\begin{array}{l}\text { Primary endpoint: ACR20 } \\
\text { ACR50, ACR70 } \\
\text { Tender/swollen joint counts, pain VAS, } \\
\text { physician/patient global, duration morning } \\
\text { stiffness, HAQ } \\
\text { Adverse events }\end{array}$ \\
\hline Bathon 2000 [15] & 632 & $<3$ years & $\begin{array}{l}\text { ETN } 10 \mathrm{mg} \text { twice/week + placebo } \\
\text { ETN } 25 \mathrm{mg} \text { twice/week + placebo } \\
\text { Placebo twice/week + MTX }\end{array}$ & 1 years & $\begin{array}{l}\text { Primary endpoint: ACR-N, change in modified } \\
\text { Sharp score } \\
\text { ACR20, ACR } 50, \text { ACR70 } \\
\text { Adverse events }\end{array}$ \\
\hline $\begin{array}{l}\text { Keystone } 2004 \\
\quad[16]\end{array}$ & 420 & $\begin{array}{l}\text { Mean } \\
8.9 \text { years }\end{array}$ & $\begin{array}{l}\text { ETN } 50 \mathrm{mg} \text { once/week + placebo } \\
\text { ETN } 25 \mathrm{mg} \text { twice/week } \\
\text { Placebo twice/week (then ETN } \\
\quad 25 \mathrm{mg} \text { twice/week after } 8 \text { weeks) }\end{array}$ & 16 weeks & $\begin{array}{l}\text { Primary endpoint: ACR20 } \\
\text { ACR50, ACR70 } \\
\text { Serum drug levels }\end{array}$ \\
\hline $\begin{array}{l}\text { Klareskog } 2004 \\
\text { (TEMPO) [17] }\end{array}$ & 686 & $\begin{array}{l}6 \text { months to } \\
20 \text { years }\end{array}$ & $\begin{array}{l}\text { ETN } 25 \mathrm{mg} \text { twice/week + MTX } \\
\text { ETN } 25 \mathrm{mg} \text { twice/week + placebo } \\
\text { Placebo twice/week + MTX }\end{array}$ & 3 years & $\begin{array}{l}\text { Primary endpoint: ACR-N AUC; modified total } \\
\text { Sharp score } \\
\text { ACR20, ACR50, ACR70, DAS, DAS remission, } \\
\text { HAQ } \\
\text { Adverse events }\end{array}$ \\
\hline Combe 2006 [19] & 260 & $\begin{array}{l}\text { Mean } \\
6.6 \text { years }\end{array}$ & $\begin{array}{l}\text { ETN } 25 \mathrm{mg} \text { twice/week + placebo } \\
\text { Placebo twice/week + SSZ } \\
\text { ETN } 25 \mathrm{mg} \text { twice/week + SSZ }\end{array}$ & 2 years & $\begin{array}{l}\text { Primary endpoint: ACR20 } \\
\text { ACR50, ACR70, DAS44-ESR, morning stiffness } \\
\quad \text { duration } \\
\text { HAQ, EQ-5D VAS } \\
\text { Adverse events }\end{array}$ \\
\hline $\begin{array}{l}\text { Emery } 2008 \\
\quad(\text { COMET) [18] }\end{array}$ & 542 & $\begin{array}{l}3 \text { months to } \\
2 \text { years }\end{array}$ & $\begin{array}{l}\text { ETN } 50 \mathrm{mg} \text { once/week + MTX } \\
\text { Placebo once/week + MTX }\end{array}$ & 2 years & $\begin{array}{l}\text { Primary endpoints: DAS } 28 \text { remission }(<2.6) \text {, } \\
\text { change in van der Heijde modified total } \\
\text { Sharp score } \\
\text { HAQ, employment status } \\
\text { Adverse events }\end{array}$ \\
\hline
\end{tabular}

ETN etanercept, SSZ sulfasalazine, $M T X$ methotrexate, $A U C$ area under the curve, $A C R-N$ American College of Rheumatology N index of improvement, $V A S$ visual analogue scale, $H A Q$ Health Assessment Questionnaire

other bDMARDs have been published [23-26]. A Cochrane review of previous bDMARD meta-analyses found similar efficacy between etanercept and adalimumab, infliximab, abatacept and rituximab, with etanercept seeming to cause fewer treatment withdrawals due to AEs than adalimumab or infliximab [27]. However, more recent Cochrane metaanalyses with the additional comparators of golimumab, certoliuzmab and tofacitinib reported no clinically meaningful differences in outcomes or withdrawal rates across four RA populations defined by prior treatment exposure and/or response [28-31]; safety profiles were largely comparable but insufficient to provide conclusions regarding risk of malignancy. Another recent systematic review found similar rates of serious AEs (SAEs) between etanercept and abatacept, adalimumab, golimumab, rituximab and tofacitinib with potentially higher rates of SAEs in certolizumab and tocilizumab in the first 6 months of treatment [32]. Regarding cost-effectiveness, a systematic review comparing etanercept, adalimumab and infliximab for the treatment of RA was favourable towards etanercept; the incremental cost-effectiveness ratio (ICER) for etanercept was $£ 24,000$ per quality of life year (QALY) in comparison to $£ 30,000$ per QALY for adalimumab and $£ 38,000$ per QALY for infliximab [33].

\section{Etanercept Biosimilars}

Presently, the etanercept biosimilar SB4 (Benepali) is approved for use in RA by the EMA and GP2015 (Erelzi) is approved for use in RA by both the EMA and the FDA. Both SB4 and GP2015 phase III RCTs will be reviewed 
regarding clinical outcomes, safety profiles and trial characteristics with reference to the RCTs for the RP.

The etanercept biosimilar YLB113 has completed phase III trials and was submitted for EMA approval in May 2018 [34], but the data is not currently accessible via PubMed for this review. Phase III trial data are available for HD203 (Davictrel@) which was licenced in South Korea but subsequently withdrawn, LBEC0101 (EuceptC) licenced in Japan and South Korea, and CHS-0214 (in abstract form [35]) which is currently only marketed in the Caribbean and Latin America. Additional biosimilars that are not approved by the EMA or FDA but are available elsewhere worldwide includes Etacept (Cipla@) in India.

\section{SB4 (Benepali)}

Samsung's SB4 was approved by the EMA in June 2017. The manufacturer demonstrated that SB4 and the RP were highly similar in structure, function and pharmacokinetics in healthy male subjects [36]. For RA, a phase III, double blind, randomised equivalence study was performed comparing SB4 to the RP with published results at both 24 [37] and 52 weeks [38]. The trial included 596 patients with moderate to severe RA despite a minimum of 6 months MTX treatment without prior bDMARD exposure. All patients were required to take concomitant MTX (10-25 mg/week) throughout the trial period. The primary endpoint was ACR2 0 with an equivalence margin of $-15 \%$ to $15 \%$ in line with EMA guidelines [39].

The proportion of patients meeting ACR20 in the perprotocol set (PPS) was $78.1 \%$ for SB4 and $80.3 \%$ for the RP at week 24 , and $80.8 \%$ for SB4 and $81.5 \%$ for the RP at week 52 , demonstrating equivalence (results from the full analysis set (FAS) were similar). There was no significant difference in secondary endpoints between the two groups, although trends marginally favoured SB4 at week 52 (ACR50 58.5\% vs $53.2 \%$; ACR70 $37.5 \%$ vs $31.0 \%$, for SB4 and RP, respectively); mean improvement in DAS28 and HAQ also favoured SB4, as did mean change in total Sharp score (mTSS) for radiographic progression [38].

There were no statistically significant differences in rates of AEs between groups other than for injection site reactions (ISRs): $3.7 \%$ in the SB4 group compared to $17.5 \%$ in the RP group at week $52(p<0.001)$. Further analysis published separately regarding ISRs in relation to ADA status found no conclusive evidence to explain this difference, although the authors suggest that this may be related to differences in formation composition and material differences (unlike the RP, the SB4 needle does not contain L-arginine or latex) [40]. SAEs were slightly more common in the SB4 group at $6 \%$ compared to $5.1 \%$ in the RP, although only one SAE was treatment associated in the SB4 group compared to 6 in the $\mathrm{RP}$ group. Although not included in the RCT manuscript, the
EMA Assessment Report noted a difference between groups when AEs are grouped in to hepatobiliary disorders, but was concluded by the EMA not to be treatment related. Additionally, there were four malignancies in the SB4 group compared to one in the RP group, but the EMA remarked that these numbers were too low to conclude on significance [41]. Regarding immunogenicity, incidence of ADAs was significantly lower in the SB4 group at week 52 (1\% compared to $13.2 \%)$. However, only one RP patient developed ADA titres of neutralising capacity with the majority of ADAs being transient; therefore, the clinical relevance of this is unclear, particularly over longer periods of treatment [38].

In the open label extension, a smaller subset of patients in the RP arm were switched to SB4 for a further 52 weeks. This demonstrated sustained and comparable clinical efficacy and safety outcomes between groups, suggesting that there are no adverse outcomes associated with switching from the RP to SB4. One patient per group developed non-neutralising levels of ADAs [42].

\section{GP2015 (Erelzi)}

GP2015 from Sandoz was approved by the FDA in 2016 and the EMA in 2017. The pharmacokinetics of GP2015 were shown to be highly similar to the RP in structure, function and pharmacokinetics in healthy male subjects [43]. The approval for GP2015 in RA has been extrapolated from the EGALITY study, comparing GP2015 and the RP in 531 patients with plaque psoriasis which met the primary endpoint [44]. Patients were randomised at 12 weeks to continue treatment or to switch between products on a six weekly basis for a further 18 weeks without a negative impact on efficacy or an increase in ADAs.

Similarly to SB4, ISRs were higher in the RP group compared to GP2015 (14.2\% vs 4.9\%). There were no clinically meaningful differences in AEs or SAEs, although overall rates of treatment emergent AEs of special interest, including herpes infection, fungal infections, neutropenia and other dermatological diagnoses (detailed in the study's supplementary material) were higher in the continued GP2015 group vs. continued RP group (11\% vs. $4.7 \%$ ) and in the switched GP2015 vs switched RP group (11\% vs 5\%). Regarding immunogenicity, no patients in the GP2015 developed ADAs. Four patients in the continued RP and one patient in the RP switchers group developed ADAs, all of which were transient [44].

The EQUIRA study comparing RP and GP2015 for moderate to severe RA with an inadequate response to MTX was completed in June 2017 [45] with week 24 results published in abstract form (ACR20 88.8\% vs 93.6\%, ACR50 63.9\% vs $71.2 \%$ and ACR70 $33.7 \%$ vs $42.9 \%$ for GP2015 and RP, respectively) [46]. The primary outcome of mean change from baseline of DAS28-CRP was within the pre-specified 
equivalence margin. The rates of SAEs were $0.5 \%$ vs $3.2 \%$ for GP2015 vs RP with similar findings as reported for SB4 regarding frequency of ISRs: $7.0 \%$ to $17.9 \%$ for GP2015 and $\mathrm{RP}$, respectively. There were low levels of transient ADAs detected with no significant levels present in either group at week 24. The full manuscript is required to review this data in more detail. Recently, abstract data regarding switching between RP and GP2015 was published with no significant impact on efficacy or safety at week 48 [47].

\section{HD203}

HD203 was approved for use in South Korea but upon request of the manufacturer was subsequently withdrawn from the market after the manufacturing facility was sold. Following publication of pharmacokinetic data demonstrating biosimilarity [48], a phase III multicentre double-blinded RCT was performed in South Korea comparing the RP at $25 \mathrm{mg}$ twice weekly to HD203, both in combination with MTX. The proportion of patients achieving ACR50 was statistically significantly greater in the HD203 group at week 24 and week 48 in the PPS (and at week 24 in the FAS) but not ACR20 or ACR70 at any time point; therefore, this is unlikely to be of clinical significance. In the PPS dataset, the response rates were as follows for HD203 and the RP: ACR20 87.3\% to $86.5 \%$, ACR50 $68.2 \%$ to $54.5 \%$, and ACR70 $38.2 \%$ to $33.9 \%$ (reported in the manuscripts supplementary data).

Overall, there were no significant differences in clinical outcomes, safety or immunogenicity between the groups. The difference in rates of ISRs between groups was less significant than for the two biosimilars outlined above; $2 \%$ compared to $5.5 \%$ for HD203 and the RP, respectively [49].

\section{LBEC0101}

At the time of writing, LBEC0101 has been approved for use in Japan and South Korea but not by the EMA or FDA. Following publication of pharmacokinetic data demonstrating biosimilarity [50], a phase III multicentre double-blinded RCT was performed in Japan and South Korea comparing the RP at $50 \mathrm{mg}$ weekly to LBEC0101, both in combination with MTX [51]. Patients who had been previously exposed to $\geq 2$ bDMARDs or to etanercept were excluded; $16 \%$ of patients had previous bDMARD exposure. However, no exclusions were made based on comorbidity other than active tuberculosis. The primary endpoint of mean change in DAS28-ESR from baseline at week 52 was -3.01 (95\% CI - 3.198, $2.820)$ in the LBEC0101 group and -2.86 (95\% CI - 3.051, $-2.667)$ in the RP group, meeting the pre-specified equivalence margin of -0.6 to 6 . ACR20, 50 and 70 responses comparing LBEC0101 to RP at week 52 were as follows: $92.0 \%$ vs $88.4 \%, 74.7 \%$ vs $65.8 \%$ and $58.0 \%$ vs $50.0 \%$.

Rates of AEs are much higher in this study than reported elsewhere: $92 \%$ in the LBEC0101 group and $92.5 \%$ in the RP group. Rates of SAEs were $16.6 \%$ and $10.7 \%$ respectively and although rates of SAEs related to treatment were $7 \%$ in both groups. Of note, rates of hepatic function abnormalities were doubled in the LBEC0101 group at $6.4 \%$ compared to $3.2 \%$, although the definition of abnormal hepatic function is not described. Again, ISRs were more frequent in the RP group at $34.2 \%$ compared to $10.2 \%$, and ADAs were more frequent in the RP group at $9.6 \%$ compared to $1.6 \%$.

\section{Equivalence and Switching}

It has been noted that clinical responses in biosimilar and RP comparator trials may report different responses for the RP than reported in pivotal RP trials. For example, PASI75 response of the etanercept RP group (76\%) in the EGALITY study was much higher than in previous RP studies $(47 \%$ to $49 \%)[44,52,53]$.

The pivotal RCTs for etanercept outlined above reported variable ACR20 responses across a variety of time points, with varying patient populations and previous/current treatment exposure, making comparisons difficult (Fig. 1). All etanercept biosimilar trials compared the biosimilar and RP in combination with MTX due to pivotal RP trial data supporting greater clinical responses in combination therapy. The RCTs for both SB4 and HD203 chose patients who have failed on $\geq 6$ months of MTX. The two trials have reasonably comparable baseline data regarding age, gender and disease duration although the HD203 trial patients had a lower baseline swollen joint count (SJC), tender joint count (TJC) and HAQ than the SB4 trial patients. Interestingly, the performance of the RP is relatively similar in these two trials (Fig. 2). Comparing 48-week RP data in the HD203 trial to the 52-week RP data in the SB4 trial is as follows: ACR20 $81.5 \%$ to $86.5 \%$, ACR50 $53.2 \%$ to $54.5 \%$ and $31.0 \%$ to $33.9 \%[38,48]$.

Higher ACR responses were reported for the RP in the LBEC0101 RCT with rates of ACR20, 50 and 70 reported at $88.4 \%, 65.8 \%$ and $50 \%$, respectively. This cannot be explained fully by ethnicity, as the HD203 RCT was also conducted in Asia, although the majority of recruitment sites in the LBEC0101 RCT were in Japan as opposed to South Korea. The higher ACR responses for RP are somewhat surprising given that $16 \%$ of patients in this trial had previous bDMARD exposure, as patients with prior bDMARD failure are less likely to respond to a subsequent bDMARD [54, 55], although the reason for previous bDMARD discontinuation (inefficacy or AE) was not discussed. The rates of AEs and SAEs were also notably higher in this RCT, which could be 
Fig. 2 Differences in patient characteristics between pivotal $\mathrm{RP}$ and biosimilar etanercept trials (ETN, etanercept RP)
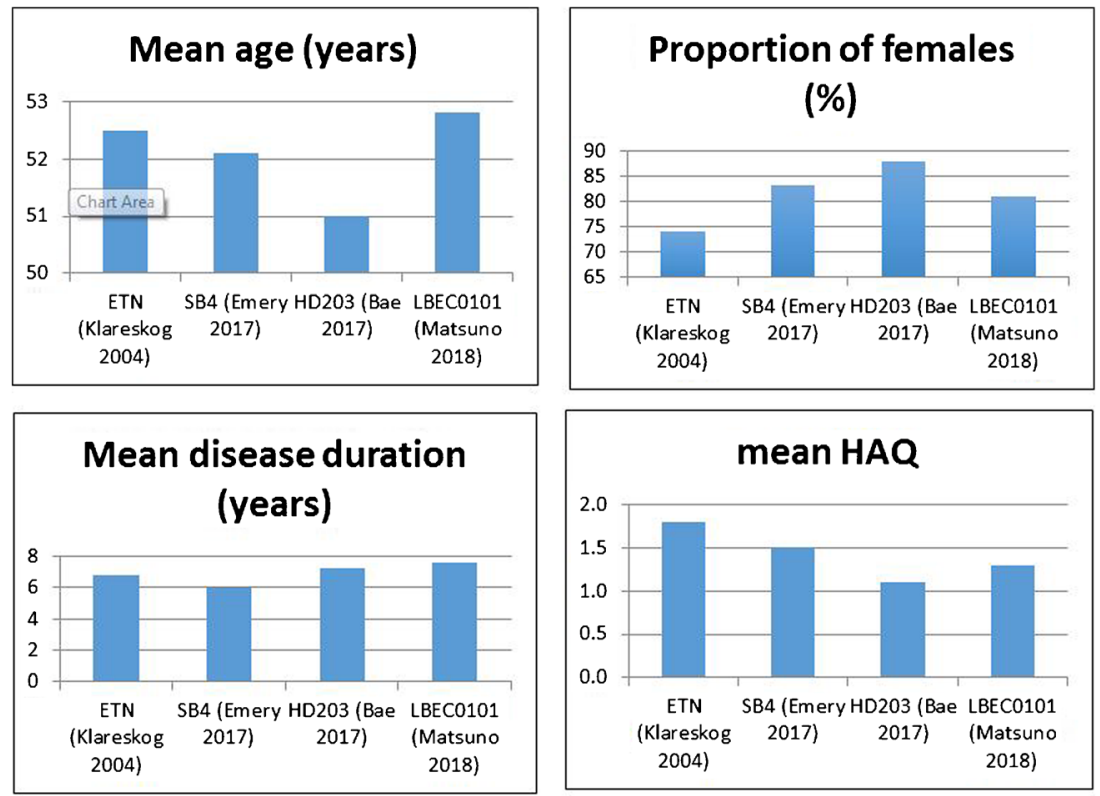

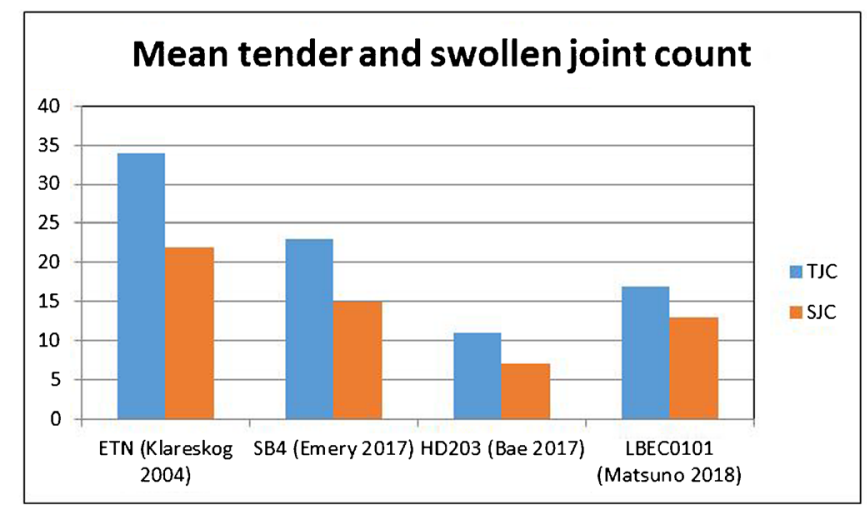

linked to the exclusion criteria not featuring comorbidities in contrast to the other RCTs discussed (Figs. 2 and 3).

The RP RCT most similar to the biosimilar RCTs is the TEMPO study, which assessed RP and MTX combination therapy, although patients with MTX exposure in the prior 6 months or previous MTX failure were ineligible and the patients had a significantly greater baseline SJC and TJC than in the biosimilar RCTs. The ACR20 response of $85 \%$ at 52 weeks was comparable to the RP data from biosimilar trials, whereas the ACR50 and ACR70 responses were significantly higher at
Fig. 3 Differences in ACR response rates for the RP in pivotal and biosimilar etanercept trials (ACR70 not reported for ETN Moreland 1997)

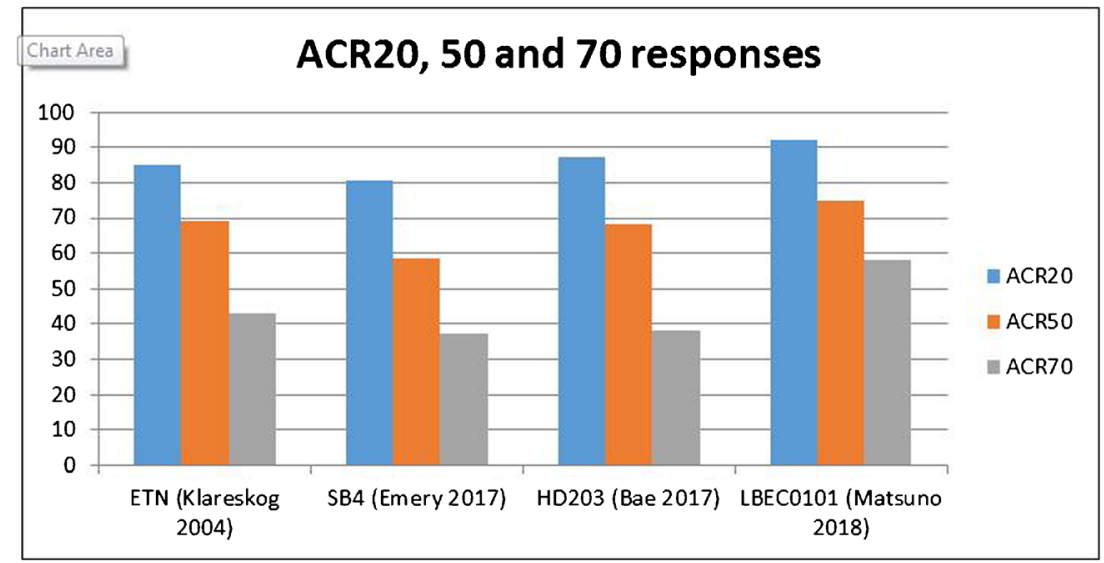


$69 \%$ and $43 \%$, respectively [17]. In all other pivotal RP trials measuring ACR20, responses for RP were significantly lower, but the majority were studying monotherapy. Only one trial reporting ACR20 used combination therapy, reporting ACR20, 50 and 70 at $71 \%, 39 \%$ and $15 \%$, respectively, but featured significantly younger patients with much greater disease duration than other RP trials and featured only 89 patients, limiting the ability to make comparative comments [14].

With only one phase III RCT for each biosimilar, it is difficult to draw meaningful conclusions regarding the risk of SAEs, with severe infections and malignancy being rare events in both the biosimilar and RP groups. Additionally, these RCTs have stringent inclusion and exclusion criteria which are not reflective of real-world practice and limits the generalisability of these findings. Data regarding ISRs and development of ADAs does appear to favour biosimilar etanercept use over RP. This is additionally supported by an international survey of 149 nurses which reported preference for the SB4 autoinjector over the RP autoinjector for ease of use [56]. However, patient preferences regarding switching or remaining on their established treatment will differ and must be taken into account. Although not in a RA patient group, the switching between biosimilar and RP in the EGALITY trial did not appear to alter AE profiles or immunogenicity, supporting the safety of switching where appropriate, and clinical outcomes and safety/immunogenicity profiles were sustained in the SB4 switching open label extension study [42].

\section{Conclusion}

Biosimilar etanercept products are now available to RA patients in numerous countries, with the potential to significantly reduce the financial burden of treating RA worldwide. Robust trial evidence has demonstrated that SB4 and HD203 meet prespecified biosimilarity criteria and are non-inferior to the RP for RA, with similar results for GD2015 in plaque psoriasis. The ability to extrapolate licence indications without data supporting the use of that product in certain indications may create uncertainty for prescribers. Real-world efficacy and safety data via pharmacovigilance studies will therefore be essential to gather clinical evidence of the benefits and risks of switching in all patients, such as the BENEFIT trial monitoring patients switching between the RP and SB4 [57]. The continued development and approval of biosimilar products for etanercept and other bDMARDS offer exciting prospects regarding future access and opportunities in the treatment of RA worldwide.

\section{Compliance with Ethical Standards}

Conflicts of Interest EM has received research grants, funding and has been an advisor for Abbvie, BMS, Gema, Lilly, Novartis, Pfizer, Sandoz, Sanofi and Roche.
RJM has received research grant funding, acted as a scientific advisor to or spoken at meetings sponsored by Abbvie, AKL, Biogen, BMS, Chugai, Eli Lilly, Genzyme, Hospira, MSD, Novartis, Pfizer, Regeneron, Roche, Sandoz, Sanofi and UCB Pharma; funding includes both bio-originator and biosimilar companies.

Human and Animal Rights and Informed Consent This article does not contain any studies with human or animal subjects performed by any of the authors.

Open Access This article is distributed under the terms of the Creative Commons Attribution 4.0 International License (http:// creativecommons.org/licenses/by/4.0/), which permits unrestricted use, distribution, and reproduction in any medium, provided you give appropriate credit to the original author(s) and the source, provide a link to the Creative Commons license, and indicate if changes were made.

\section{References}

1. AMGEN (2018) Enbrel® (etanercept). https://www.enbrel.com/. Accessed 10 Jul 2018.

2. National Institute for Health and Clinical Excellence (2006) Adalimumab, etanercept and infliximab for the treatment of rheumatoid arthritis.

3. Bonafede MMK, Gandra SR, Watson C, Princic N, Fox KM. Cost per treated patient for etanercept, adalimumab, and infliximab across adult indications: a claims analysis. Adv Ther. 2012;29: 234-48.

4. Norman P. Enbrel and etanercept biosimilars: a tale of two patent systems. Pharm Pat Anal. 2017;6:5-7.

5. U.S. Department of Health and Human Services, Food and Drug Administration, Center for Drug Evaluation and Research (CDER) $\mathrm{C}$ for BE and R (CBER). (2015) Scientific Considerations in Demonstrating Biosimilarity to a Reference Product Guidance for Industry.

6. European Medicines Agency (2014) Guideline on similar biological medicinal products containing biotechnology-derived proteins as active substance: non-clinical and clinical issues.

7. McCamish M, Pakulski J, Sattler C, Woollett G. Toward interchangeable biologics. Clin Pharmacol Ther. 2015;97:215-7.

8. Goffe B, Cather JC. Etanercept: an overview. J Am Acad Dermatol. 2003;49:105-11.

9. Zhou H. Clinical pharmacokinetics of etanercept: a fully humanized soluble recombinant tumor necrosis factor receptor fusion protein. J Clin Pharmacol. 2005;45:490-7.

10. European Medicines Agency (2018) Enbrel (Etanercept). http:// www.ema.europa.eu/ema/index.jsp?curl=pages/medicines/human/ medicines/000262/human med 000764 .jsp\&mid= WC0b01ac058001d124. Accessed 10 Jul 2018.

11. Tracey D, Klareskog L, Sasso EH, Salfeld JG, Tak PP. Tumor necrosis factor antagonist mechanisms of action: a comprehensive review. Pharmacol Ther. 2008;117:244-79.

12. Moots RJ, Xavier RM, Mok CC, Rahman MU, Tsai WC, al-Maini $\mathrm{MH}$, et al. The impact of anti-drug antibodies on drug concentrations and clinical outcomes in rheumatoid arthritis patients treated with adalimumab, etanercept, or infliximab: results from a multinational, real-world clinical practice, non-interventional study. PLoS One. 2017;12:e175207.

13. Moreland LW, Schiff MH, Baumgartner SW, Tindall EA, Fleischmann RM, Bulpitt KJ, et al. Etanercept therapy in rheumatoid arthritis. A randomized, controlled trial. Ann Intern Med. 1999;130:478-86. 
14. Weinblatt ME, Kremer JM, Bankhurst AD, Bulpitt KJ, Fleischmann RM, Fox RI, et al. A trial of etanercept, a recombinant tumor necrosis factor receptor:Fc fusion protein, in patients with rheumatoid arthritis receiving methotrexate. N Engl J Med. 1999;340:253-9.

15. Bathon JM, Martin RW, Fleischmann RM, Tesser JR, Schiff MH, Keystone EC, et al. A comparison of etanercept and methotrexate in patients with early rheumatoid arthritis. N Engl J Med. 2000;343: 1586-93.

16. Keystone EC, Schiff MH, Kremer JM, Kafka S, Lovy M, DeVries $\mathrm{T}$, et al. Once-weekly administration of $50 \mathrm{mg}$ etanercept in patients with active rheumatoid arthritis: results of a multicenter, randomized, double-blind, placebo-controlled trial. Arthritis Rheum. 2004;50:353-63.

17. Klareskog L, van der Heijde D, de Jager JP, Gough A, Kalden J, Malaise M, et al. Therapeutic effect of the combination of etanercept and methotrexate compared with each treatment alone in patients with rheumatoid arthritis: double-blind randomised controlled trial. Lancet. 2004;363:675-81.

18. Emery P, Breedveld FC, Hall S, Durez P, Chang DJ, Robertson D, et al. Comparison of methotrexate monotherapy with a combination of methotrexate and etanercept in active, early, moderate to severe rheumatoid arthritis (COMET): a randomised, double-blind, parallel treatment trial. Lancet. 2008;372:375-82.

19. Combe B, Codreanu C, Fiocco U, Gaubitz M, Geusens PP, Kvien TK, et al. Efficacy, safety and patient-reported outcomes of combination etanercept and sulfasalazine versus etanercept alone in patients with rheumatoid arthritis: a double-blind randomised 2-year study. Ann Rheum Dis. 2009;68:1146-52.

20. Felson DT, Anderson JJ, Boers M, Bombardier C, Chernoff M, Fried B, et al. The American College of Rheumatology preliminary core set of disease activity measures for rheumatoid arthritis clinical trials. The committee on outcome measures in rheumatoid arthritis clinical trials. Arthritis Rheum. 1993;36:729-40.

21. van der Heijde D, Klareskog L, Rodriguez-Valverde V, Codreanu $\mathrm{C}$, Bolosiu H, Melo-Gomes J, et al. Comparison of etanercept and methotrexate, alone and combined, in the treatment of rheumatoid arthritis: two-year clinical and radiographic results from the TEMPO study, a double-blind, randomized trial. Arthritis Rheum. 2006;54:1063-74.

22. Kameda H, Ueki Y, Saito K, Nagaoka S, Hidaka T, Atsumi T, et al. Etanercept (ETN) with methotrexate (MTX) is better than ETN monotherapy in patients with active rheumatoid arthritis despite MTX therapy: a randomized trial. Mod Rheumatol. 2010;20:531-8.

23. Singh JA, Christensen R, Wells GA, Suarez-Almazor ME, Buchbinder R, Lopez-Olivo MA, et al. A network meta-analysis of randomized controlled trials of biologics for rheumatoid arthritis: a Cochrane overview. CMAJ. 2009;181:787-96.

24. Devine EB, Alfonso-Cristancho R, Sullivan SD. Effectiveness of biologic therapies for rheumatoid arthritis: an indirect comparisons approach. Pharmacotherapy. 2011;31:39-51.

25. Donahue KE, Gartlehner G, Jonas DE, Lux LJ, Thieda P, Jonas BL, et al. Systematic review: comparative effectiveness and harms of disease-modifying medications for rheumatoid arthritis. Ann Intern Med. 2008;148:124-34.

26. Gartlehner G, Hansen RA, Jonas BL, Thieda P, Lohr KN. The comparative efficacy and safety of biologics for the treatment of rheumatoid arthritis: a systematic review and metaanalysis. J Rheumatol. 2006;33:2398-408.

27. Singh JA, Christensen R, Wells GA, Suarez-Almazor ME, Buchbinder R, Lopez-Olivo MA, et al. Biologics for rheumatoid arthritis: an overview of Cochrane reviews. Cochrane Database Syst Rev. 2009. https://doi.org/10.1002/14651858.CD007848. pub2.

28. Singh JA, Hossain A, Tanjong Ghogomu E, Kotb A, Christensen R, Mudano AS, Maxwell LJ, Shah NP, Tugwell P, Wells GA (2016)
Biologics or tofacitinib for rheumatoid arthritis in incomplete responders to methotrexate or other traditional disease-modifying anti-rheumatic drugs: a systematic review and network meta-analysis. Cochrane Database Syst Rev CD012183.

29. Singh JA, Hossain A, Tanjong Ghogomu E, Mudano AS, Tugwell P, Wells GA. Biologic or tofacitinib monotherapy for rheumatoid arthritis in people with traditional disease-modifying anti-rheumatic drug (DMARD) failure: a Cochrane systematic review and network meta-analysis (NMA). Cochrane Database Syst Rev. 2016;11: CD012437.

30. Singh JA, Hossain A, Tanjong Ghogomu E, Mudano AS, Maxwell LJ, Buchbinder R, et al. Biologics or tofacitinib for people with rheumatoid arthritis unsuccessfully treated with biologics: a systematic review and network meta-analysis. Cochrane Database Syst Rev. 2017;3:CD012591.

31. Singh JA, Hossain A, Mudano AS, Tanjong Ghogomu E, SuarezAlmazor ME, Buchbinder R, et al. Biologics or tofacitinib for people with rheumatoid arthritis naive to methotrexate: a systematic review and network meta-analysis. Cochrane Database Syst Rev. 2017;5:CD012657.

32. Tarp S, Eric Furst D, Boers M, et al. Risk of serious adverse effects of biological and targeted drugs in patients with rheumatoid arthritis: a systematic review meta-analysis. Rheumatology. 2016;56: kew442.

33. Chen Y-F, Jobanputra P, Barton P, Jowett S, Bryan S, Clark W, FrySmith A, Burls A (2006) A systematic review of the effectiveness of adalimumab, etanercept and infliximab for the treatment of rheumatoid arthritis in adults and an economic evaluation of their costeffectiveness. Health Technol Assess 10:iii-iv, xi-xiii, 1-229.

34. Lupin (2018) Lupin submits marketing authorization application for etanercept biosimilar in Europe. http://www.lupin.com/lupinsubmits-marketing-authorization-application-for-etanerceptbiosimilar-in-europe.php. Accessed 10 Jul 2018.

35. O'Dell J, Takeuchi T, Tanaka Y, Louw I, Tiabut T, Kai M, et al. OP0226 randomized, double-blind study comparing Chs-0214 with etanercept in patients with active rheumatoid arthritis (RA) despite methotrexate (MTX) therapy. Ann Rheum Dis. 2016;75(143):1143.

36. Lee YJ, Shin D, Kim Y, Kang J, Gauliard A, Fuhr R. A randomized phase 1 pharmacokinetic study comparing SB4 and etanercept reference product (Enbrel®) in healthy subjects. Br J Clin Pharmacol. 2016;82:64-73.

37. Emery P, Vencovský J, Sylwestrzak A, Leszczyński P, Porawska W, Baranauskaite A, et al. A phase III randomised, double-blind, parallel-group study comparing SB4 with etanercept reference product in patients with active rheumatoid arthritis despite methotrexate therapy. Ann Rheum Dis. 2017;76:51-7.

38. Emery P, Vencovský J, Sylwestrzak A, Leszczyński P, Porawska W, Baranauskaite A, et al. 52-week results of the phase 3 randomized study comparing SB4 with reference etanercept in patients with active rheumatoid arthritis. Rheumatology. 2017;56:2093-101.

39. Committee for Medicinal Products for Human Use (CHMP) (2005) Guideline on the choice of the non-inferiority margin. http://www. emea.eu.int. Accessed 8 Jul 2018.

40. Girolomoni G, Feldman SR, Emery P, Ghil J, Keum JW, Cheong $\mathrm{SY}$, et al. Comparison of injection-site reactions between the etanercept biosimilar SB4 and the reference etanercept in patients with rheumatoid arthritis from a phase III study. Br J Dermatol. 2018;178:e215-6.

41. Committee for Medicinal Products for Human Use (CHMP), European Medicines Agency (2015) Benepali.

42. Emery P, Vencovský J, Sylwestrzak A, Leszczyński P, Porawska W, Stasiuk B, et al. Long-term efficacy and safety in patients with rheumatoid arthritis continuing on SB4 or switching from reference etanercept to SB4. Ann Rheum Dis. 2017;76:1986-91. 
43. von Richter O, Skerjanec A, Afonso M, et al. GP2015, a proposed etanercept biosimilar: pharmacokinetic similarity to its reference product and comparison of its autoinjector device with prefilled syringes. Br J Clin Pharmacol. 2017;83:732-41.

44. Griffiths CEM, Thaçi D, Gerdes S, Arenberger P, Pulka G, Kingo $\mathrm{K}$, et al. The EGALITY study: a confirmatory, randomized, doubleblind study comparing the efficacy, safety and immunogenicity of GP2015, a proposed etanercept biosimilar, vs. the originator product in patients with moderate-to-severe chronic plaque-type psoriasis. Br J Dermatol. 2017;176:928-38.

45. Comparative Efficacy and Safety Study of GP2015 and Enbrel® in Patients With Rheumatoid Arthritis-Full Text ViewClinicalTrials.gov. https://clinicaltrials.gov/ct2/show/NCT02638259. Accessed 23 Sep 2018.

46. Kavanaugh A, Allanore Y, Kucharz EJ, Babic G (2017) Etanercept biosimilar GP2015 has equivalent efficacy and safety to etanercept originator in patients with moderate to severe rheumatoid arthritis: the Phase 3 Equira Study-ACR Meeting Abstracts. Arthritis Rheumatol. 69 (suppl 10):

47. Matucci-Cerinic M, Schulze-Koops H, Buch M, Kavanaugh A, Allanore Y, Kucharz EJ, et al. FRI0129 switch between reference etanercept (ETN) and gp2015, an etanercept biosimilar, did not impact efficacy and safety in patients with moderate-to-severe rheumatoid arthritis: 48 -week results from the phase 3 equira study. Ann Rheum Dis. 2018;77:609.

48. Yi S, Kim SE, Park M-K, Yoon SH, Cho J-Y, Lim KS, et al. Comparative pharmacokinetics of HD203, a biosimilar of etanercept, with marketed Etanercept (Enbrel®). BioDrugs. 2012;26:177-84.

49. Bae S-C, Kim J, Choe J-Y, Park W, Lee SH, Park YB, et al. A phase III, multicentre, randomised, double-blind, active-controlled, parallel-group trial comparing safety and efficacy of HD203, with innovator etanercept, in combination with methotrexate, in patients with rheumatoid arthritis: the HERA study. Ann Rheum Dis. 2017;76:65-71.

50. Lee H, Chung H, Lee S, Lee H, Yang SM, Yoon SH, et al. LBEC0101, a proposed etanercept biosimilar: pharmacokinetics, immunogenicity, and tolerability profiles compared with a reference biologic product in healthy male subjects. BioDrugs. 2017;31:349-55.

51. Matsuno H, Tomomitsu M, Hagino A, Shin S, Lee J, Song YW. Phase III, multicentre, double-blind, randomised, parallel-group study to evaluate the similarities between LBEC0101 and etanercept reference product in terms of efficacy and safety in patients with active rheumatoid arthritis inadequately responding to methotrexate. Ann Rheum Dis. 2018;77:488-94.

52. Leonardi CL, Powers JL, Matheson RT, Goffe BS, Zitnik R, Wang A, et al. Etanercept as monotherapy in patients with psoriasis. $\mathrm{N}$ Engl J Med. 2003;349:2014-22.

53. Tyring S, Gottlieb A, Papp K, Gordon K, Leonardi C, Wang A, et al. Etanercept and clinical outcomes, fatigue, and depression in psoriasis: double-blind placebo-controlled randomised phase III trial. Lancet. 2006;367:29-35.

54. Smolen JS, Kay J, Doyle MK, Landewé R, Matteson EL, Wollenhaupt J, et al. Golimumab in patients with active rheumatoid arthritis after treatment with tumour necrosis factor $\alpha$ inhibitors (GO-AFTER study): a multicentre, randomised, double-blind, placebo-controlled, phase III trial. Lancet. 2009;374:210-21.

55. Karlsson JA, Kristensen LE, Kapetanovic MC, Gulfe A, Saxne T, Geborek P. Treatment response to a second or third TNF-inhibitor in RA: results from the south Swedish arthritis treatment group register. Rheumatology. 2007;47:507-13.

56. Thakur K, Biberger A, Handrich A, Rezk MF. Perceptions and preferences of two etanercept autoinjectors for rheumatoid arthritis: a New European Union-approved etanercept biosimilar (Benepali®) versus Etanercept (Enbrel®) - findings from a nurse survey in Europe. Rheumatology (Oxford) 2016;3:77-89.

57. National Library of Medicine Clinical Trials Database (2017) Observational study to evaluate the real-life effectiveness of benepali following transition from Enbrel-full text viewClinicalTrials.gov. https://clinicaltrials.gov/ct2/show/ NCT03100734. Accessed 15 Jul 2018. 